\title{
Development of Novel Low-temperature Curable Positive-Tone Photosensitive Polyimide with High Elongation
}

\author{
Yu Shoji, Yutaro Koyama, Yuki Masuda, Keika Hashimoto, Kimio Isobe, and Ryoji Okuda \\ Electronic \& Imaging Materials Research Laboratories, Toray Industries, Inc. \\ 3-1-2 Sonoyama, Otsu-Shi, Shiga-Ken 520-0842, Japan \\ E-mail:Yutaro_Koyama@nts.toray.co.jp
}

\begin{abstract}
Recently, progress of semiconductor packaging is drastic and multi-pinned devices such as Fan-out Wafer Level Packages (FOWLPs) attract much attention. For those applications, photosensitive polyimides (PSPIs) are applied as re-distribution layers (RDLs) and they are required to have high level of properties such as adhesion to metal and reliability. We developed novel low-temperature curable positive-tone photosensitive polyimides (posi-PSPIs) with high elongation, strong adhesion to the copper RDLs, and high chemical resistance for establishing the multi RDLs by improving the base-polyimides and incorporating polyimides with cross-linkers and adhesion promoters.
\end{abstract}

Keywords: polyimides, redistribution layers, photo-sensitive, low temperature curable, high elongation

\section{Introduction}

As the package size of integrated circuits (ICs) and pin-pitches of the devices dramatically decrease, the integrated multi-layered distribution technologies for IC chips have been developed due to their high performance, low fabrication costs, and miniaturization. Recently, dielectric materials for re-distribution layers (RDLs) have been focused on for the multi-pinned devices such as Fan-out Wafer Level Packages (FOWLPs), which is the one of the latest packaging trends in microelectronics [1-3]. There are a few requirements for dielectric materials as follows: the low-temperature curable nature $\left(<250{ }^{\circ} \mathrm{C}\right)$ because the devices are embedded by the molded compound with low heat resistance, the strong adhesion to the copper RDLs, high chemical resistance, and high reliability in the multi-layered dielectric materials after the reliability test, for instance thermal humidity test, thermal cycle, and high-impact test, and so on [4].

In this study, we have developed the novel low-temperature curable positive-tone photosensitive dielectric materials for RDLs by using the characteristic pre-imidized PI. Various types of low temperature curable PSPIs named LT series and LT-S series have been released for customer requirements such as low residual stress, high photosensitivity, and high glass transition temperature $\left(T_{\mathrm{g}}\right)$. Moreover, the low-temperature curable cross-linkers and the adhesion promoters have been introduced to meet the customer requirements. However, the high-impact resistance of such dielectric materials still remains. In this recent study, the electric materials with high elongation are also described to achieve the high reliability toward the high-impact test because that property can be related to enhancing the durability of materials.

\section{Experimental}

2.1. Measurement

Number- and weight-average molecular weights $\left(M_{\mathrm{n}}\right.$ and $\left.M_{\mathrm{w}}\right)$ were measured by size exclusion chromatography (SEC) on Waters Model 510 equipped with a pump, a UV absorbance detector, and two polystyrene gel columns of TSK Gel $\alpha-2500$ and TSK Gel $\alpha-4000$ (TOSOH) based on 
a conventional calibration curve using polystyrene standards. $N$-Methylpyrrolidone (NMP) containing $50 \mathrm{mmol} \mathrm{L}^{-1}$ of $\mathrm{LiCl}$ and $50 \mathrm{mmol} \mathrm{L}^{-1}$ of $\mathrm{H}_{3} \mathrm{PO}_{4}$ $\left(40^{\circ} \mathrm{C}\right)$ was used as a carrier solvent at a flow rate of $0.4 \mathrm{~mL} \mathrm{~min}^{-1}$. FT-IR spectra were measured on a Horiba FT-720 spectrometer. ${ }^{1} \mathrm{H}$ NMR spectra were recorded with a JEOL JNM-EX270 spectrometer. Thermal analysis was performed on a Seiko EXSTAR 6000 TG/DTA6200 thermal analyzer at a heating rate of $10{ }^{\circ} \mathrm{C} \min ^{-1}$ for thermogravimetry (TG) and a Seiko EXSTAR $6000 \mathrm{TMA} / \mathrm{SS} 6100$ thermal analyzer at a heating rate of $5{ }^{\circ} \mathrm{C} \mathrm{min}^{-1}$ for glass transition temperature $\left(T_{\mathrm{g}}\right)$ and coefficient of thermal expansion (CTE) measurement. Residual stress of cured samples on silicon wafer was evaluated on FLX-3300-T (TOHO) by measuring the curvature radius using a laser at room temperature. Mechanical properties of films such as tensile strength, young's modulus, and elongation were measured on TENSILON at a speed of $5 \mathrm{~mm} \mathrm{~min}^{-1}$. Electric properties of films such as volume resistance, surface resistance, and breakdown voltage were measured by using LCR meter. To observe the cross-sectional patterns using a scanning electron microscope (SEM) with secondary electrons (FE-SEM S-4800, Hitachi Ltd.), the specimens were treated to $\mathrm{Pt} / \mathrm{Pd}$ sputtering. Film thickness was measured by STM-802 (Lambda $\AA$, SCREEN). The acceleration tests as reliability tests were carried out by treating the film on the substrate with Temperature and Humidity Chamber (PI-2ST, TABAI ESPEC CORP.) as Thermal Humidity Storage (THS) test and with Thermal Shock Chamber (TSE-11-A, ESPEC CORP.) as Thermal Cycle (TC) test.

\subsection{Materials Preparation}

PI was obtained by reacting tetracarboxylic dianhydrides with diamines in $20 \mathrm{wt} \%$ NMP at $160^{\circ} \mathrm{C}$ for 4 hours under $\mathrm{N}_{2}$ gas flow.

The PSPI varnish sample was prepared by following procedure. The dried PI $(3.51 \mathrm{~g})$, diazonaphthoquinone (DNQ, $0.62 \mathrm{~g}$ ), and cross-linker $(0.12 \mathrm{~g})$ were mixed into $5.75 \mathrm{~g}$ of $\gamma$-butyrolactone (GBL). The solution was filtered through a $0.2 \mu \mathrm{m}$ pore poly(tetrafluoroethylene) filter to remove the particles.

\subsection{Pattern formation}

The varnish sample was coated on an 8 -in $\mathrm{Si}$ wafer by a spin-coater (ACT-8, Tokyo-Electron). Then, the coated wafer was soft-baked at $120{ }^{\circ} \mathrm{C} \times 180 \mathrm{sec}$ on a hot plate
(ACT-8). The film was exposed by an i-line stepper (Nikon, NSR-2005i9C) from $200 \mathrm{~mJ} \mathrm{~cm}^{-2}$ to $800 \mathrm{~mJ} \mathrm{~cm}^{-2}$. The exposed film was developed by $2.38 \%$ tetramethylammonium hydroxide aqueous solution (TMAHaq) at $23{ }^{\circ} \mathrm{C}$. Finally, the PSPI patterned on wafer was cured in a clean oven (CLH-21CD (V)-S, KOYO THERMOSYSTEMS Co., Ltd) at a condition of $170-250{ }^{\circ} \mathrm{C}$ for $60 \mathrm{~min}$ under $\mathrm{N}_{2}$ atmosphere.

\subsection{Evaluation method of adhesion}

Tape peeling test was carried out to the cured PSPI on copper plated silicon. This test was also conducted after pressure cooker test (PCT) at a condition of $121{ }^{\circ} \mathrm{C}, 2 \mathrm{~atm}$, and $100 \% \mathrm{RH}$ (Figure 1). In addition to the peeling test, the observation of the cross-sectional area for copper patterned substrate coating PSPIs was carried out by the treatment of die singulation with a diamond blade, ion milling using a cross-section polisher (Argon ion beam, $6.0 \mathrm{kV}, 7 \mathrm{sccm}, 7 \mathrm{hrs}$ ), and FE-SEM observation, or by the FIB-SEM treatment with the condition of $40 \mathrm{kV}$ for $10 \mathrm{hrs}$, respectively.

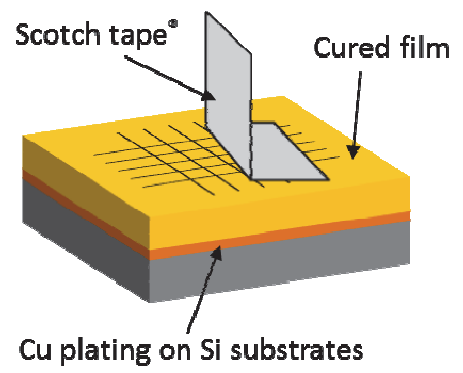

<Classitication>

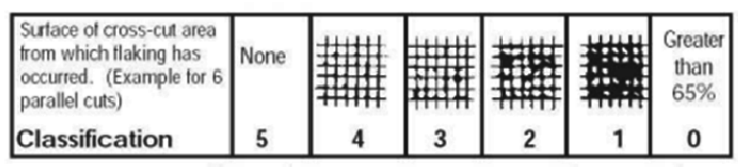

Figure 1. Schematic illustration of the tape peeling test for the evaluation of copper adhesion.

\subsection{Chemical resistance test}

Wafer chips with cured film of patterned PSPI were immersed in various types of solvent for several conditions. The resulting PSPI patterns were evaluated by microscope to clarify the generation of crack or delamination.

\section{Results and discussion}

3.1. Preparation and Pattern Formation of PSPI

Conventional positive-tone photosensitive polyimide is composed of alkali soluble polyimide precursor and napthoquinonediazide photosensitive 
compound (DNQ) [5]. In the conventional procedure for producing a polyimide, it was required to be heated up to $300{ }^{\circ} \mathrm{C}$ to complete imidization, leading to high shrinkage, outgassing, and high residual stress. Therefore, the pre-imidized polyimide was designed to improve such properties (Figure 2). The obtained polyimide, $\mathbf{P 1}$, is soluble in polar organic solvent such as NMP, dimethyl sulfoxide (DMSO), and GBL at room temperature because of introducing the bulky unit into polyimide backbones by twisting the coplanar imide rings and loosening the packing of the main chain of polymer.

$\mathbf{P 1}$ is also soluble in alkaline solution because of phenolic hydroxyl groups introduced into P1 and it can be patterned by using alkaline developer such as TMAHaq with high resolution.

The weight-average molecular weight and polydispersity index of $\mathbf{P 1}$ was determined to be 27,000 and 2.1, respectively. In the FT-IR spectrum of $\mathbf{P 1}$, the characteristic imide peaks at $1786(\mathrm{C}=\mathrm{O}$ asymmetric stretching $), 1722 \quad(\mathrm{C}=\mathrm{O}$ symmetric stretching), and $1385 \mathrm{~cm}^{-1}$ (C-N stretching) were assigned, indicating complete imidization. Also, the chemical structure of $\mathbf{P 1}$ was confirmed by ${ }^{1} \mathrm{H}$ NMR analysis.

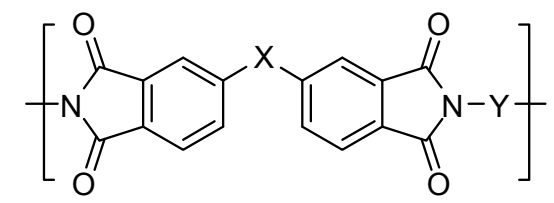

Figure 2. The chemical structure of polyimide. $\mathrm{X}$ and/or Y: rigid and flexible units.

Next, we observed the pattern shape of P1 with varnish sample which is the GBL solution of $\mathbf{P 1}$ with DNQ derivatives and thermal cross-linker (PSPI-1).

Figure 3 shows the SEM image of the obtained fine pattern.

The resolution of PSPI-1 is around $5 \mu \mathrm{m}$ and $70^{\circ}$ of the taper angle at a $7 \mu \mathrm{m}$ film thickness, which could be applicable for the metal sputtering.

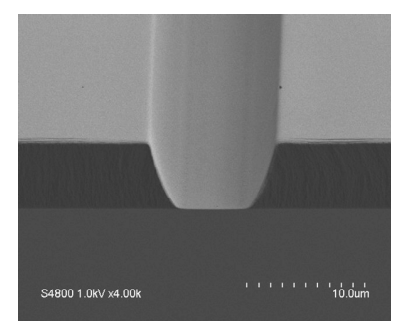

Figure 3. The $5 \mu \mathrm{m}$ line pattern of PSPI-1.

\subsection{Chemical Resistance}

Chemical resistance of the patterned PSPI-1 was tested by using following solvents: NMP, propylene glycol monomethyl ether acetate (PGMEA), DMSO, acetone, isopropanol (IPA), 1\% HFaq, aquous mixture of $\mathrm{H}_{2} \mathrm{SO}_{4}$ and $\mathrm{H}_{2} \mathrm{O}_{2}(4 / 1$ w/w), 2.38\% TMAHaq, and 25\% NaOHaq. PSPI-1 showed the high resistance to all solvents above and its pattern have not changed after the test, indicating that the degree of curing is enough for PSPI-1 and it is suitable as a low temperature curing material.

\subsection{Thermal and Mechanical Properties}

The thermal properties of PSPI-1 were evaluated by TG and TMA at the heating ratio of $10{ }^{\circ} \mathrm{C} \mathrm{min}-1$ and $5{ }^{\circ} \mathrm{C} \mathrm{min}^{-1}$, respectively. PSPI-1 possessed a relatively high thermal stability over $350{ }^{\circ} \mathrm{C}$ ( $5 \%$ weight loss temperature, $\left.T_{\mathrm{d} 5 \%}\right)$, and PSPI-1 showed the glass transition at over $150{ }^{\circ} \mathrm{C}$ and about $60 \mathrm{ppm}{ }^{\circ} \mathrm{C}^{-1}$ of CTE by TMA, which was the relatively high thermal stability among low temperature cured materials. This high thermal stability is attributed to the polyimide backbone and the low temperature curable thermal cross-linker.

\subsection{Adhesion to Copper}

The adhesion of PSPI-1 to copper was evaluated by a tape peeling test as shown in Figure 1 . PSPI-1 has high adhesion strength to copper classified with ' 5 ' even after the PCT test, indicating that PSPI-1 is applicable as an insulation layer for RDLs without any delamination between PSPI-1 and copper layer. The strong adhesion to copper of PSPI-1 was probably caused by the interaction between the polar imide group and the copper surface [6].

\subsection{LT Series}

Based on PSPI-1, various types of low temperature curable PSPIs were developed for the customer requirements as LT series (Table 1).

\subsection{For high reliability}

As mentioned in the beginning, high reliability of the multi-layered package is considered when the insulating materials for RDLs are developed. So far, the mechanical property, especially elongation $(>40 \%)$, is anticipated to be a key factor toward high reliability without generating any crack and breaking RDLs. Hence, we have impr- 
Table 1. Physical properties of LT series.

\begin{tabular}{|c|c|c|c|c|c|}
\hline Properties & Cure & LT-6100 & LT-6300 & LT-6500 & LT-6600 \\
\hline $\begin{array}{c}\text { Terisile strenglh } \\
/ \text { MPa }\end{array}$ & $200^{\circ} \mathrm{C}$ & 100 & 110 & 121 & 112 \\
\hline \multirow{3}{*}{$\begin{array}{l}\text { F.lomgation } \\
/ \%\end{array}$} & $170^{\circ} \mathrm{C}$ & 30 & 30 & 30 & 30 \\
\hline & $200^{\circ} \mathrm{C}$ & 20 & 20 & 20 & 20 \\
\hline & $250^{\circ} \mathrm{C}$ & 20 & 20 & 20 & 20 \\
\hline $\begin{array}{c}\text { Young's } \\
\text { modulus/ Gpa }\end{array}$ & $200^{\circ} \mathrm{C}$ & 2.6 & 2.6 & 3.4 & 2.9 \\
\hline $\mathrm{CTE} / \mathrm{ppm} \cdot{ }^{\circ} \mathrm{C}^{-1}$ & $200^{\circ} \mathrm{C}$ & 70 & 61 & 65 & 60 \\
\hline \multirow{3}{*}{$\begin{array}{c}\text { Resixhlual stress } \\
\text { /Mpa }\end{array}$} & $170^{\circ} \mathrm{C}$ & 13 & 13 & 21 & 13 \\
\hline & $200^{\circ} \mathrm{C}$ & 13 & 21 & 35 & 20 \\
\hline & $250^{\circ} \mathrm{C}$ & 25 & 23 & 39 & 26 \\
\hline \multirow{2}{*}{$T_{\text {d5\% }} /{ }^{\circ} \mathrm{C}$} & $200^{\circ} \mathrm{C}$ & 382 & 374 & 393 & 367 \\
\hline & $250^{\circ} \mathrm{C}$ & 388 & 380 & 412 & 371 \\
\hline \multirow{2}{*}{$T_{\mathrm{g}}$ (TMA) $/{ }^{\circ} \mathrm{C}$} & $200^{\circ} \mathrm{C}$ & 160 & 180 & 232 & 194 \\
\hline & $250^{\circ} \mathrm{C}$ & - & 201 & 287 & 212 \\
\hline $\begin{array}{c}\text { Dielectric } \\
\text { Constant } \\
\end{array}$ & \multirow{4}{*}{$200^{\circ} \mathrm{C}$} & 3.7 & 3.4 & 3.1 & 3.4 \\
\hline $\begin{array}{c}\text { Volume } \\
\text { Iesistance/ W cm }\end{array}$ & & $>10^{16}$ & $>10^{16}$ & $>10^{16}$ & $>10^{16}$ \\
\hline $\begin{array}{c}\text { Surface } \\
\text { resistance/ W }\end{array}$ & & $>10^{16}$ & $>10^{16}$ & $>10^{16}$ & $>10^{16}$ \\
\hline $\begin{array}{c}\text { Breakdown } \\
\text { woltage/ } / \mathrm{kV} \mathrm{mm}^{-1}\end{array}$ & & $>420$ & 395 & $>420$ & $>420$ \\
\hline $\begin{array}{c}\text { Water } \\
\text { absorption/\% }\end{array}$ & $200^{\circ} \mathrm{C}$ & 1.7 & 1.3 & 1.1 & 1.6 \\
\hline
\end{tabular}

oved the elongation property of LT-series. The concept of enhancing elongation is shown in Figure 4. The improved polyimide, P2, with flexible molecular units in a part of P1 was introduced to enhance the elongation property of the obtained film, which is assumed to increase the entanglement of each polymer chain.

(a) P1
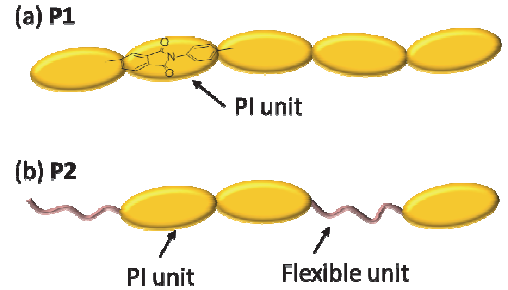

Figure 4. The design concept for enhancing elongation. (a) Pre-imidized polyimide, P1, (b) P1 with a part of flexible unit, $\mathrm{P} 2$.

Fine PSPI-2 patterns were successfully obtained in the thickness range of 5 to $15 \mu \mathrm{m}$. After curing at $220{ }^{\circ} \mathrm{C}$ for $60 \mathrm{~min}$, the obtained fine patterns are shown in Figure 5, and mechanical and thermal properties are summarized in Table 2. The obtained PSPI-2 film exerted the excellent elongation property over two times higher than that of LT-series. It was assumed that the effective entanglement of each polymer chain caused high elongation by introducing flexible unit in the polymer backbone. In addition, thermal humidity storage (THS) test and thermal cycle (TC) test for PSPI-2 were demonstrated as quasi-reliability test.

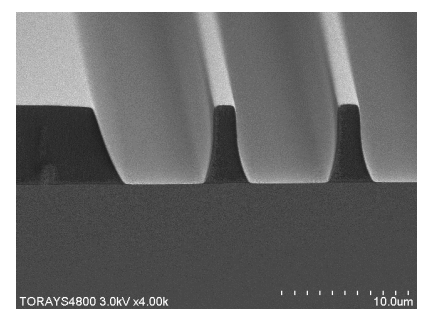

Figure 5. The $5 \mu \mathrm{m}$ line $\&$ space pattern of PSPI-2.

Table 2. Mechanical and thermal properties of PSPI-2.

\begin{tabular}{|c|c|c|}
\hline \multirow{2}{*}{ Properties } & \multicolumn{2}{|c|}{$\mathbf{2 2 0}^{\circ} \mathbf{C}, \mathbf{6 0}$ min } \\
\cline { 2 - 3 } & $\begin{array}{c}\text { Before } \\
\text { THS }^{\mathbf{a}}\end{array}$ & $\begin{array}{c}\text { After } \\
\mathbf{T H S}^{\mathbf{a}}\end{array}$ \\
\hline Tensile strength/ $\mathrm{MPa}$ & 140 & 135 \\
\hline Elongation $/ \%$ & 70 & 70 \\
\hline Young's modulus/ GPa & 3.0 & 3.1 \\
\hline$T_{\mathrm{g}}(\mathrm{TMA}) /{ }^{\circ} \mathrm{C}$ & 275 & 275 \\
\hline $\mathrm{CTE} / \mathrm{ppm}{ }^{\circ} \mathrm{C}^{-1}$ & 54 & 54 \\
\hline
\end{tabular}

a Thermal humidity storage (THS) test at a condition of JEDEC Level 1. (85 $\left.{ }^{\circ} \mathrm{C}, 85 \% \mathrm{RH} 168 \mathrm{hrs}\right)$

(a)

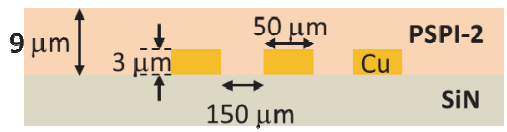

(b)
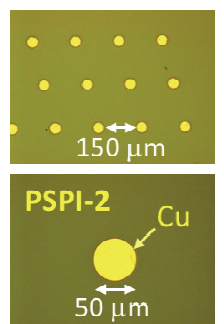

(c)
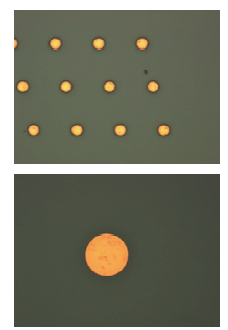

(d)

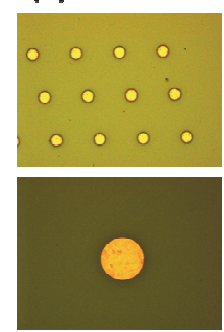

Figure 6. The top views for PSPI-2 coating on the copper-pad substrate at a curing condition of $180^{\circ} \mathrm{C}$ for $1 \mathrm{hr}$. (a) Illustration of the structure for PSPI-2 coated on the copper-pad patterned substrate. (b) After curing, (c) after the 10 times reflow treatment at $270{ }^{\circ} \mathrm{C}$ for 1 min, and (d) additional 200 cycle TC test at a condition from -65 to $150{ }^{\circ} \mathrm{C}$ after the reflow treatment.

Thermal and mechanical properties of PSPI-2 have not changed even after THS, meaning the promised reliability in the package system without generating any crack and breaking RDLs. In fact, no crack was observed in the cured film coating on the $\mathrm{Cu}$-pad patterned substrate even after TC test at a condition from -65 to $150{ }^{\circ} \mathrm{C}$ (Figure 6).

Chemical resistance of the patterned PSPI-2 
was also investigated by using several solvents summarized in Table 3. As a result, PSPI-2 shows the good chemical stability and its pattern have not changed after the treatment to all tested solvent (Figure 7).

Table 3. Chemical resistance for patterned PSPI-2.

\begin{tabular}{|c|c|c|}
\hline Solvent & $\begin{array}{c}\text { Conditions } \\
\text { (Temp./ Time) }\end{array}$ & $\begin{array}{c}\text { Results } \\
\text { of thickness change }\end{array}$ \\
\hline Acetone & $25^{\circ} \mathrm{C} / 30 \mathrm{~min}$ & less than $3 \%$ \\
\hline $\mathrm{IPA}$ & $25^{\circ} \mathrm{C} / 30 \mathrm{~min}$ & less than $3 \%$ \\
\hline $2.38 \%$ TMAHaq & $25{ }^{\circ} \mathrm{C} / 30 \mathrm{~min}$ & less than $3 \%$ \\
\hline $\begin{array}{c}\text { Stripper } \\
\text { (DMSO-base) }\end{array}$ & $60{ }^{\circ} \mathrm{C} / 30 \mathrm{~min}$ & less than $10 \%$ \\
\hline NMP & $60{ }^{\circ} \mathrm{C} / 30 \mathrm{~min}$ & less than $10 \%$ \\
\hline $\begin{array}{c}\text { Flux } \\
(\text { water-base) }\end{array}$ & $250^{\circ} \mathrm{C} / 60 \mathrm{sec}$ & less than $5 \%$ \\
\hline $30 \% \mathrm{H}_{2} \mathrm{O}_{2}$ & $50{ }^{\circ} \mathrm{C} / 30 \mathrm{~min}$ & less than $3 \%$ \\
\hline $10 \% \mathrm{H}_{2} \mathrm{SO}_{4}$ & $25{ }^{\circ} \mathrm{C} / 30 \mathrm{~min}$ & less than $3 \%$ \\
\hline $10 \% \mathrm{H}_{3} \mathrm{PO}_{4}$ & $25{ }^{\circ} \mathrm{C} / 30 \mathrm{~min}$ & less than $3 \%$ \\
\hline $2 \% \mathrm{HFaq}^{\circ}$ & $25{ }^{\circ} \mathrm{C} / 10 \mathrm{~min}$ & less than $3 \%$ \\
\hline
\end{tabular}

Cure condition: $220^{\circ} \mathrm{C}$ for $1 \mathrm{~h}$.

a DMSO (67-73\%)+NMP (15-25\%)+organic amine $(3.5-4.5 \%)$ (a)

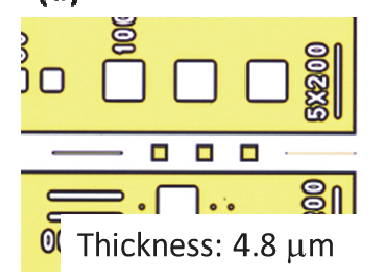

(b)

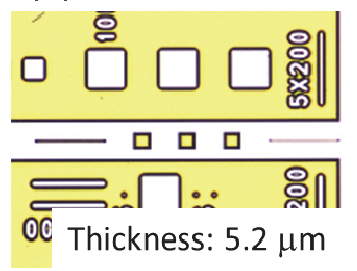

Figure 7. Optical microscope images of patterned PSPI-2 (a) before/(b) after the treatment with a DMSO-based stripper.

Next, the adhesion of PSPI-2 to copper was evaluated by a tape peeling test, and PSPI-2 possesses enough high adhesion strength to copper no less than LT series, classified with ' 5 ' even after the PCT test.

Moreover, in order to evaluate the more precise copper adhesion of PSPI-2, the observation of the cross-sectional area for PSPI-2 coated on the copper patterned substrate as shown in Figure 8. Before the observation of the cross-sectional area, the fabrication of specimens is necessary to obtain clear images. There are a few methods to fabricate them as follow. One is the continuous fabrication of polishing and observation by applying FIB-SEM. The other is polishing the cross-sectional area by ion beam using argon to achieve a flat cross-sectional area after roughly cutting the specimen, and then the processed cross-sectional area can be observed by FE-SEM. Figure 9 shows the processed specimen by FIB-SEM and its magnification image. The well adhesion of PSPI-2 to the copper surface was apparently observed as shown in Figure 9. As a result, no delamination between PSPI-2 and copper occurred, meaning high adhesion property to copper RDLs.

Electronic property of PSPI-2 was also investigated by applying the voltage to the copper patterned substrate as a copper migration test (Figure 10). The result indicates that the reliability of PSPI-2 is quite high because of keeping the resistivity even after THS test at a condition of $130{ }^{\circ} \mathrm{C} / 85 \mathrm{RH} \% / 196 \mathrm{hrs} / 10 \mathrm{~V}$.

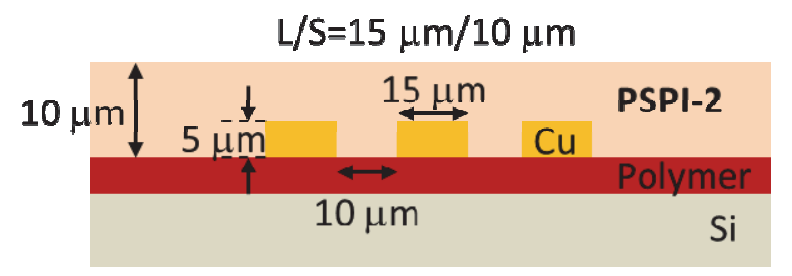

Figure 8. Illustration of the structure for PSPI-2 coated on the copper patterned substrate.

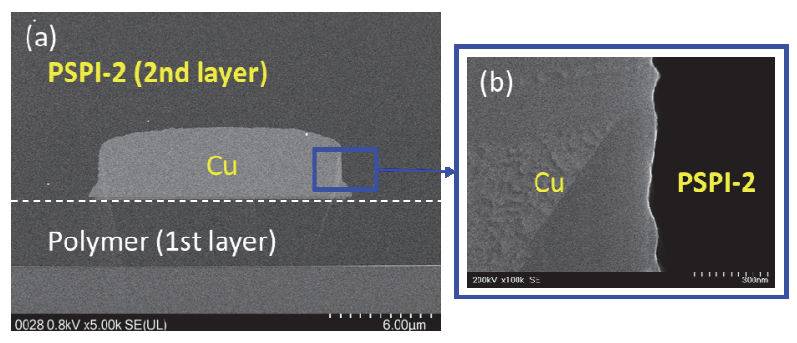

Figure 9. SEM images of the cross-sectional areas for the (a) overall view of PSPI-2 after the FIB treatment at a condition of $40 \mathrm{kV}$ for 10 hours, and (b) the magnified one.

Based on PSPI-2, novel low temperature curable positive-tone photosensitive dielectric materials with high elongation were developed as LT-S series, named LT-S8000s.

In the course of this study, it was found that LT series and LT-S series had high sensitivity, good chemical resistance, excellent copper adhesion, and high elongation which are desirable to achieve the promised reliability as RDL dielectric materials, especially for FOWLPs. 


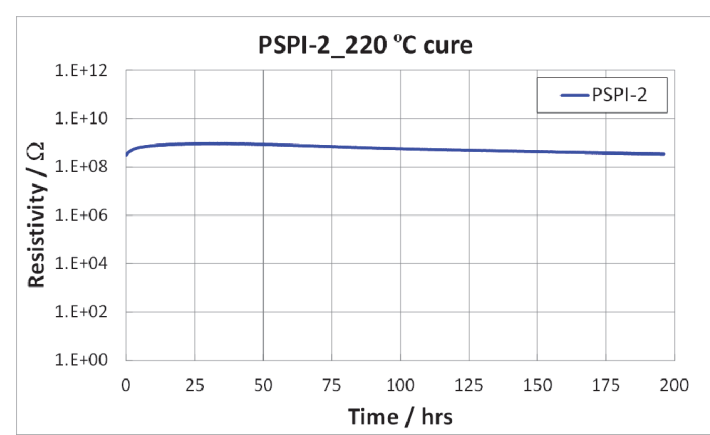

Figure 10. Resistivity of PSPI-2 cured for $220^{\circ} \mathrm{C}$ for 1 hour during the treatment at a condition of $130{ }^{\circ} \mathrm{C}$, $85 \mathrm{RH} \%$, and $10 \mathrm{~V}$ bias for $196 \mathrm{hrs}$.

\section{Conclusion}

We have developed the novel low-temperature curable positive-tone photosensitive dielectric materials for RDLs by using the characteristic pre-imidized PI. Various types of low temperature curable PSPIs named as LT series show low residual stress, high photosensitivity, excellent adhesion to copper, and high $T_{\mathrm{g}}$ up to $230{ }^{\circ} \mathrm{C}$ for customer requirements.

We have also developed the novel low-temperature curable positive-tone photosensitive dielectric materials with the high elongation property for RDLs, named as LT-S series. The high elongation concept contains the introduction of the flexible molecular unit in the base polymer backbone, which is assumed to increase the entanglement of each polymer chain. As a result, the composition based on the above polymer and the conventional low-temperature curable cross-linkers cured at below $250{ }^{\circ} \mathrm{C}$ show the high elongation property up to $70 \%$. In addition, the pattern fabrication process of the developed dielectric material was carried out, and the fine patterns were obtained with high resolution and high sensitivity developed by $2.38 \%$ TMAHaq solution as an alkaline developer. Moreover, the obtained patterned material possesses high chemical resistance toward the DMSO-based resist stripper, and the excellent adhesion to copper and the constant resistivity after the quasi-reliability test. This material is expected to be a key material by contributing to enhance the next-generation semiconductor device packaging reliability.

\section{References}

1. J. Azemar, "Fan-Out and Embedded Die: Technologies \& Market Trends," Yole Development, Market \& Technology Report (2015).

2. A. Cardoso, M. Pires, and R. Pinto, "Thermally Enhanced FOWLP-Development of a Power-eWLB Demonstrator," Proc. IEEE Electronic Components and Technology Conference (ECTC 2015), IEEE press (2015) p1682.

3. Y. Lin, E. Chong, M. Chan, K. H. Lim, and S. W. Yoon, "WLCSP+ and eWLCSP in FlexLine: Innovative Wafer Level Package Manufacturing," Proc. IEEE Electronic Components and Technology Conference (ECTC 2015), IEEE press (2015) p865.

4. B. Singh, V. Smet, J. Lee, G. Menezes, M. Kobayashi, P. M. Raj, V. Sundaram, B. Roggeman, U. Ray, R. Radojcic, and R. Tummala, "First Demonstration of Drop-test Reliability of Ultra-thin Glass BGA Packages Directly Assembled on Boards for Smartphone Applications," Proc.IEEE Electronic Components and Technology Conference (ECTC 2015), IEEE press (2015) p1566.

5. M. Tomikawa, R. Okuda, and H. Ohnishi, $J$. Photopolym. Sci. Technol., 28, 73 (2015)

6. W.-J. Lee, Y.-S. Lee, S.-K. Rha, Y.-J. Lee, K.-Y. Lim, Y.-D. Chung, and C.-N. Whang, Appl. Surf. Sci., 205 (2003) 128. 